\title{
Is there malaria transmission in urban settings in Colombia?
}

\author{
Julio C. Padilla', Pablo E. Chaparro², Karen Molina ${ }^{3,5}$, Myriam Arevalo-Herrera ${ }^{3,4}$ and Sócrates Herrera ${ }^{*}$
}

\begin{abstract}
Background: Colombia contributes a significant proportion of malaria cases in the Americas, which are predominantly rural. However, in the last 8 years $10 \%$ of the endemic municipalities have also reported urban and periurban malaria cases, a growing concern for health authorities. This study focused on the characterization of the officially reported urban malaria cases.

Methods: A descriptive retrospective study based on secondary information provided by the Colombian National Surveillance System-SIVIGILA for the 2008-2012 period was conducted. A total of 17 municipalities with consistent and persistent reports of urban and peri-urban malaria were selected for analysis, which included site of origin and of residence, age, gender and ethnicity of patients, health system affiliation, Plasmodium species and the presence of malaria vectors.
\end{abstract}

Results: A total of 18,113 malaria cases were reported from urban and peri-urban areas of 17 endemic municipalities. Almost $70 \%$ of the reports originated in localities in the departments of Chocó and Nariño, located on the Pacific Coast where a predominantly Afro-Colombian population, of individuals of under 30 years of age, was the most affected (80.7 \%), mainly with Plasmodium falciparum infections (52.1\%). Median annual parasite index (API) was 6.4 per 1000 inhabitants (3.4 in 2008; 10.8 in 2010 and 6.0 in 2012). Between 2011 and 2012 complicated cases (2.4\%) and malaria in pregnant women (1.4\%) were reported. Study areas reported the presence of at least seven Anopheles species considered malaria vectors. These analyses did not allow ascertaining the presumable origin of the recorded urban cases due to the lack of a consensus on a definition of urban, peri-urban and rural limits and the lack of proper verification of the geographical source of infection.

Conclusions: The study indicates the probable presence of endemic, unstable and low-intensity malaria transmission in Colombian urban and peri-urban areas of a group of municipalities located mainly on the Pacific coast region and a few others in the eastern region. There is a need to unequivocally confirm the urban or peri-urban origin of the malaria cases reported and the transmission conditions, as well as to develop and implement new strategies for urban and peri-urban malaria control and elimination.

Keywords: Epidemiology, Malaria, Peri-urban, Urban population, Insect vectors

\section{Background}

Malaria remains an important global health problem that affects mainly poor communities in Africa, Asia and Latin America, with an estimated $\sim 198$ million clinical malaria cases and $\sim 584,000$ deaths reported worldwide in 2013 [1]. Approximately $80 \%$ of these cases were caused

\footnotetext{
*Correspondence: sherrera@inmuno.org

${ }^{5}$ Centro de Investigación Científica Caucaseco, Cali, Colombia

Full list of author information is available at the end of the article
}

by Plasmodium falciparum, $20 \%$ by Plasmodium vivax, and a more limited number of cases by the other parasite species, including Plasmodium malariae and Plasmodium ovale [1]. Although the great majority of malaria cases occur in rural areas worldwide, during the last 30 years a growing number of urban and peri-urban cases has been reported, and a number of systematic reviews have shown the impact of urbanization on malaria transmission, mainly in sub-Saharan African countries [2-4], where the annual entomological inoculation rates (EIR)

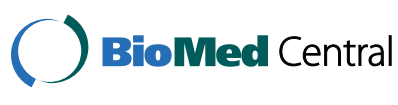

(c) 2015 Padilla et al. This article is distributed under the terms of the Creative Commons Attribution 4.0 International License (http://creativecommons.org/licenses/by/4.0/), which permits unrestricted use, distribution, and reproduction in any medium, provided you give appropriate credit to the original author(s) and the source, provide a link to the Creative Commons license, and indicate if changes were made. The Creative Commons Public Domain Dedication waiver (http://creativecommons.org/ publicdomain/zero/1.0/) applies to the data made available in this article, unless otherwise stated. 
from dozens of African cities have shown an increasing gradient from urban to peri-urban and to rural areas [2]. Likewise in Asia, malaria reemergence in countries, such as India has been associated with rapid peri-urban expansion and an increase in poverty in cities such as Mumbai, New Delhi and Chennai [5, 6]; meanwhile malaria vectors have been found to have adapted to the urban context in this country [7-9].

In Latin America, Brazil has shown a population movement tendency to urban and peri-urban areas of cities in the Amazon region due forest colonization, road construction and the establishment of agricultural and mining settlements during the last decades of the 20th century, with an enormous impact on malaria transmission [10, 11]. Between 1986 and 2005 the population in Manaus increased in the form of slums and housing projects displaying an increase in disease incidence and the annual parasite index (API) from low to medium risk and, in urban zones, from no risk to high risk $[12,13]$. In Rôndonia, another Brazilian Amazon region, the population increased 12 times between 1970 and 1990, with a consequent 30 -fold increase in malaria cases in that period [14]. Anarchical urban colonization and the presence of malaria vectors and asymptomatic carriers led to peri-urban malaria transmission in cities from this region $[14,15]$.

A similar situation exists in other Latin American countries, such as Peru, Ecuador and Colombia [9, 16, 17]. In Peru, several regions have reported peri-urban malaria transmission: Iquitos (an Amazonian city) [18], Sullana and Piura (in the Northwestern Pacific Coast) [19] and Lima (the capital city) [20]. Also Esmeraldas (San Lorenzo) in Northern Ecuador has confirmed peri-urban malaria transmission [21]. In Colombia, this problem is poorly understood, but previous studies have suggested the presence of urban and peri-urban malaria transmission foci of both $P$. vivax and P. falciparum in towns such as Quibdó, Buenaventura and Puerto Gaitán [22-24]. In all these countries peri-urban areas are characterized by rapid and anarchical urbanization induced mostly by population migration from rural endemic settings to areas with the presence of different Anopheline species. This rapid urbanization of population with poor socio-economic conditions, inadequate housing infrastructure and lack of public services, usually leads to improper sanitation, poor drainage of surface water and the consequent development of water bodies and vegetation-rich areas [22, 23]. These are suitable ecological conditions for mosquito breeding and malaria transmission. Additionally, some mosquito species appear to easily adapt to new breeding conditions in urban settings, such as water containers.
Moreover, in Colombia multiple factors, such as armed conflict, the presence of paramilitary groups, and illegal agriculture and mining, among others, significantly contribute to the displacement of rural populations to peri-urban areas in several regions. One such region is the Colombian Pacific coast, which has been reporting increasing urban and peri-urban malaria transmission $[25,26]$. This region with a length of $\sim 1300 \mathrm{~km}$ is located between Panama and Ecuador, and includes the departments of Chocó, Valle del Cauca, Cauca and Nariño and is characterized by tropical rain forests, with the highest national rainfall amounts (3000-12,000 mm annually) and is also rich in natural resources but displays the poorest social and economic development of the country. Ecological conditions in this region also favor the presence of several species of Anopheles mosquitoes, including important malaria vectors, such as Anopheles albimanus, Anopheles nuneztovari s.l. and Anopheles darlingi, which appear to have the ability to colonize a variety of breeding sites, adapting to changing environments including urban and peri-urban areas [18, 27-29]. Other regions where urban and peri-urban malaria has been reported are Puerto Gaitán and Villavicencio, both located in the Eastern Region, where ecological conditions for malaria are present and the armed conflict influences the migration of population from rural endemic settings to urban/ peri-urban dwellings. Few studies have addressed the problem at local scale in Colombia [22-24, 30] with the consequent gaps in knowledge on the real extent of urban and peri-urban malaria at national scale.

Despite growing and improving statistics and surveillance, it looks like a proportion of reported cases are actually not real urban or peri-urban cases, but the result of an erroneous classification and registration of cases, greatly due to problems regarding the following: (1) "urban setting" and "urban malaria" definitions, (2) origin of malaria cases, (3) lack of identification of mosquito breeding sites, and (4) lack of confirmation of the vector's transmission capacity in urban settings. These factors cause uncertainty about the true extent and importance of urban or peri-urban malaria transmission. Solving these issues would be critical to adjusting the strategies for malaria prevention and control in urban areas.

In conclusion, it appears that in contrast to the overall malaria decreasing trend at national level, the number of cases in urban settings is increasing and the growth rate is greater in urban than in rural settings. In response to the Millennium Development goals, Colombia has included the goal towards reducing malaria urban transmission in two recent government strategic policies: The Ten-Year Plan for Public Health (2012-2021) and the Integrated 
Management Strategy for Promotion, Prevention and Control of Vector-Borne Diseases (EGI-ETV) [31]. To contribute to this goal, this study has attempted to identify and characterize the epidemiology of urban and periurban malaria transmission in Colombia between 2008 and 2012, to establish a baseline for the current initiative of the Colombian government to significantly reduce malaria by 2021 [32].

\section{Methods}

\section{Type of study}

A descriptive study was carried out using information obtained from records compiled by SIVIGILA, from January 1, 2008 to December 31, 2012. Information was collected using standard notification forms in which the malaria clinic is assigned to the municipality defined as the geographical area bounded by the urban perimeter as defined by an administrative agreement [33] and includes both urban and peri-urban areas, as opposed to welldefined rural areas and with no correlation with population density.

Case definition was established according to the SIVIGILA protocol in which a malaria case is a patient having visited malaria endemic areas, in this case urban or peri-urban settings, in the 15 days prior to the current or recent febrile episode $\left(>37.5{ }^{\circ} \mathrm{C}\right)$ with Plasmodium infection confirmed either by thick blood smear (TBS) or rapid diagnostic test (RDT).

\section{Study sites}

Localities included in the analysis were administrative units (municipalities) corresponding to urban and periurban areas with consistent and persistent malaria cases reports to SIVIGILA. Most of these localities have been historically reported as sites with urban transmission foci and reported entomological evidence of the presence of malaria mosquito vectors according to information from the vector borne diseases (VBD) Prevention and Control Programme of the Colombian Ministry of Health $(\mathrm{MOH})$. The study focused on a total of 13 municipalities of departments located along the Pacific coast as follows: eight municipalities located in department of Chocó (Atrato, Condoto, Istmina, Litoral del Bajo San Juan, Lloró, Nóvita, Quibdó and Tadó); four in Department of Nariño (Barbacoas, El Charco, La Tola and Tumaco); and one in department of Valle del Cauca (Buenaventura). Four municipalities scattered in several departments of the central and Eastern regions of the country were also included in the analysis, namely: Pueblo Rico in department of Risaralda (central region), Puerto Inírida, in department of Guainía, Miraflores in department of Guaviare (Eastern region), and Puerto Nariño, in Amazonas department (Southern region) (Fig. 1).

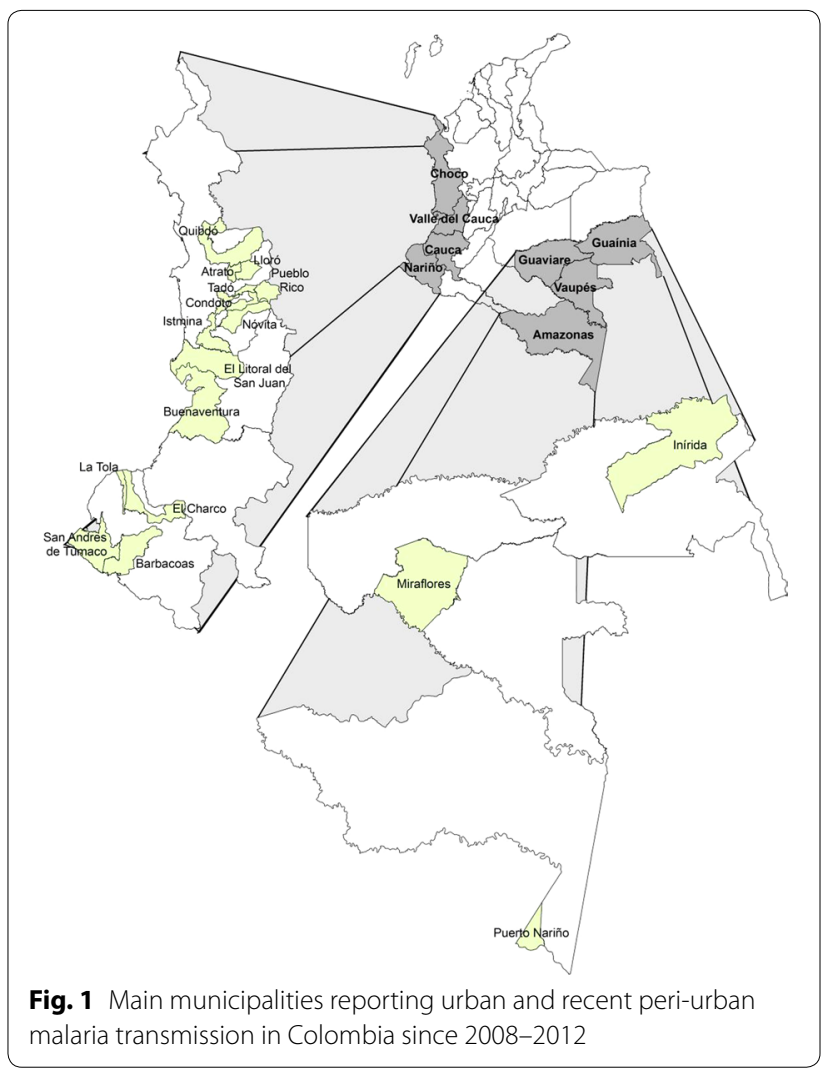

\section{Study variables}

Variables included were age, gender, ethnicity and type of health service affiliation, Plasmodium species, department and municipality of origin and of residence during the year the malaria episode was reported. Severe malaria cases and malaria in pregnant women were also included.

\section{Vector information}

Information regarding the presence of malaria vectors in each selected municipality with urban malaria was obtained from the field-work report of the Colombian National Institute of Health (Instituto Nacional de Salud, INS) and from previous publications [22, 23, 27, 28, 34].

\section{Statistical analyses}

Epidemiological and entomological variables were processed using Microsoft Excel ${ }^{\circledR}$. Univariate analysis were performed using the software Tableau statistical software version $6.0^{\circledR}$. A univariate analysis was performed for all variables. Measures of central tendency and dispersion were calculated. The API was calculated and urban population values used for each municipality were obtained from the projections of the 2005 Colombian census [35]. In order to compare the malaria morbidity profile, yearly 2008-2012 APIs were compared using a two-sample $T$ test at a 0.05 significance level to assess statistically 
significant differences between $P$. falciparum and $P$. vivax cases.

\section{Results}

In total, 18,113 malaria cases classified as urban or periurban by SIVIGILA were recorded from 2008 to 2012 with an annual average of 3623 cases, a maximum of 6133 in 2010 and a minimum of 1853 in 2008 . These cases corresponded to extreme APIs of 10.8 in 2010 and 3.4 in 2008, and an average API of 6.4 cases per 1000 inhabitants for the study period. The peak for 2010 correlates with the national malaria outbreak reported that year [36] (Fig. 2). Additionally, these cases accounted for $3.0 \%$ of the total malaria cases in Colombia in 2008 and $5.9 \%$ of cases in 2011. A moderate decline in API was observed in the 2010-2012 period. The majority of the cases (52.2\% or 9431 ), were caused by $P$. falciparum, whereas $46.1 \%$ (8356) were $P$. vivax infections, with an additional $1.6 \%$ (293) of cases due to mixed falciparum/vivax infections and $0.02 \%$ (three cases) considered non-indigenous P. malariae cases.

Over $66 \%$ of the urban and peri-urban malaria cases were reported in children and adults $<30$ years of age, with the highest incidence reported in the 20-29 age group. From this age on, cases started decreasing and the lowest incidence was reported for individuals aged over 60 . Men represented $57.3 \%$ of the malaria cases reported. The comparison between Plasmodium species showed that the API was higher in men (6.4 cases per 1000) than in women (4.8 cases per 1000) with $P$. vivax predominant $(61.2 \%)$ among men and $P$. falciparum among women (44.3\%) (Table 1).

The municipalities with the highest cumulative burden of malaria cases were Quibdó (Chocó) (4536 cases), Istmina (Chocó) (2702 cases), Tumaco (Nariño) (2441 cases), Tadó (Chocó) (1898 cases) and Nóvita (Chocó)

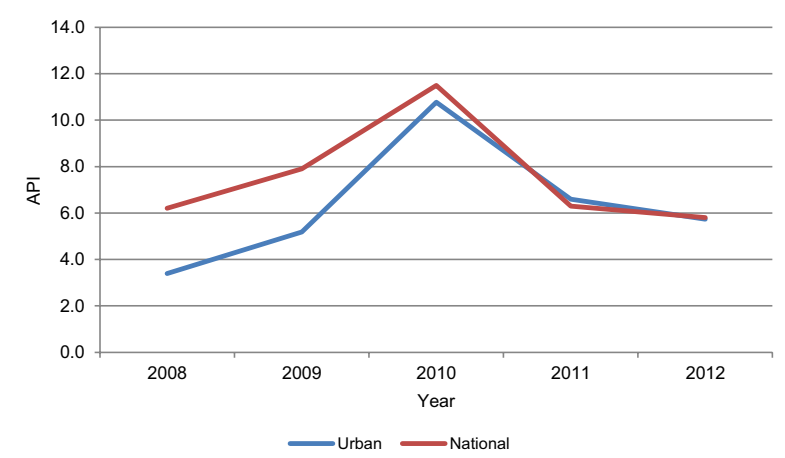

Fig. 2 Malaria incidence in Colombia from 2008 to 2012. Incidence of malaria is shown as annual parasite index (malaria cases per 1000 inhabitants) for urban settings (blue line) and the whole country (national, red line)
Table 1 Main features of urban and peri-urban malaria cases reported in Colombia by Plasmodium species from 2008 to 2012

\begin{tabular}{|c|c|c|c|c|c|}
\hline \multirow[t]{2}{*}{ Variable } & \multicolumn{2}{|c|}{$\begin{array}{l}\text { P. falciparum } \\
(n=9431)\end{array}$} & \multicolumn{2}{|c|}{$\begin{array}{l}P . \text { vivax } \\
(n=8356)\end{array}$} & \multirow[t]{2}{*}{$P$} \\
\hline & $n$ & $\%$ & $n$ & $\%$ & \\
\hline \multicolumn{6}{|l|}{ Age group } \\
\hline $0-9$ & 1450 & 15.3 & 1513 & 18.1 & 0.04 \\
\hline 10-19 & 2644 & 27.9 & 1993 & 23.9 & $<0.01$ \\
\hline $20-29$ & 2204 & 23.3 & 2080 & 24.9 & 0.22 \\
\hline $30-39$ & 1301 & 13.8 & 1167 & 14.0 & 0.89 \\
\hline $40-49$ & 954 & 10.1 & 859 & 10.3 & 0.89 \\
\hline $50-59$ & 524 & 5.5 & 461 & 5.5 & 1.00 \\
\hline $60-69$ & 236 & 2.5 & 192 & 2.3 & 0.89 \\
\hline 70-79 & 110 & 1.2 & 78 & 0.9 & 0.84 \\
\hline 80 years + & 38 & 0.4 & 13 & 0.2 & 0.92 \\
\hline \multicolumn{6}{|l|}{ Sex } \\
\hline Female & 4193 & 44.3 & 3245 & 38.8 & $<0.001$ \\
\hline Male & 5268 & 55.7 & 5111 & 61.2 & $<0.001$ \\
\hline \multicolumn{6}{|l|}{ Ethnic group } \\
\hline Indigenous & 229 & 2.4 & 609 & 7.3 & $<0.01$ \\
\hline Afro, mulato & 8632 & 91.2 & 5985 & 71.6 & $<0.001$ \\
\hline Other & 599 & 6.3 & 1761 & 21.1 & $<0.001$ \\
\hline \multicolumn{6}{|l|}{ Insurance } \\
\hline Affiliated & 6926 & 73.2 & 6300 & 75.4 & $<0.01$ \\
\hline Not affiliated & 2532 & 26.8 & 2054 & 24.6 & 0.09 \\
\hline
\end{tabular}

(1357 cases), which contributed about $70 \%$ of the total urban and peri-urban cases for the study period. However, the transmission behaviour of urban malaria in each one of these areas showed a variable trend. Novita (Chocó) presented the highest API in 2011 whereas Barbacoas (Nariño) and Buenaventura (Valle del Cauca) displayed the lowest API during this period. Tumaco (Nariño) presented with a hypo-endemic and decreasing transmission tendency. Miraflores (Guaviare) recorded a dramatic and sustained decline in the urban and periurban transmission trend (Fig. 3).

Istmina, Tadó and El Charco showed the highest annual $P$. falciparum malaria indexes ( $>14$ cases per 1000 inhabitants), whereas Miraflores and Novita exhibited the highest annual $P$. vivax malaria indexes ( $>47$ cases per 1000 inhabitants) (Table 2). Afro-descendant population was the most affected, accounting for $80.7 \%$ of the cases, whereas indigenous communities accounted for $4.6 \%$ of the cases. The remaining cases $(14.7 \%)$ occurred in ethnic minority groups.

A total of 174 of the 7242 cases $(2.4 \%)$ reported in 2011 and 2012, were classified as complicated malaria cases, most of which (146 or $83.9 \%$ ) originated in Chocó, whereas the departments of Valle del Cauca and Nariño 


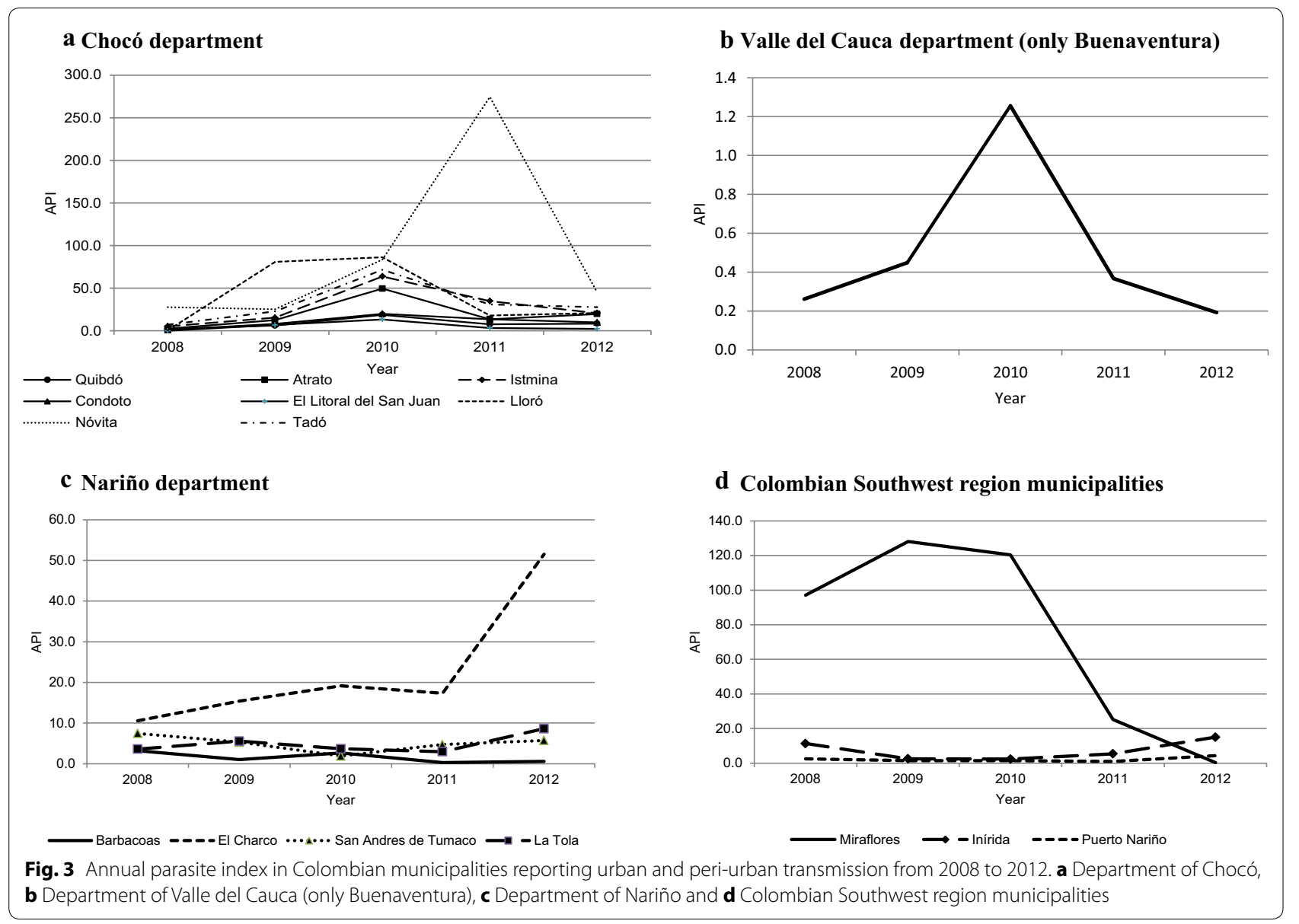

reported 19 and 7 cases, respectively. Moreover, during this period a total of 100 cases occurred in pregnant women of whom $69 \%$ were from Choco, 18 \% from Nariño, and $10 \%$ from Valle del Cauca.

The analysis of entomological data available from the Colombian INS indicates that predominant Anopheles species were: An. albimanus, An. darlingi, Anopheles neivai, Anopheles nuneztovari, Anopheles lepidotus, Anopheles pseudopunctipennis, and Anopheles punctimacula, which in general were widely distributed in peri-urban areas and most of them overlapped in the different study settings [23, 27, 28], as well as a few Anopheles spp in the urban area of Quibdó [22] (Table 3).

\section{Discussion}

This study aimed to characterize the official reports on existence of peri-urban malaria transmission in different areas in Colombia, with greater relevance in important municipalities of the Pacific coast known for the highest malaria transmission indexes in the country. Peri-urban malaria was also reported with lower indexes in areas of the central and Eastern regions of the country. In general, malaria transmission presented with a low-intensity and variable pattern, limited to areas near urban centers in a small group of municipalities.

Although at national level the overall malaria transmission presented a higher proportion of $P$. vivax cases $(\sim 70 \%)$, the distribution of the reported urban and periurban cases displayed an equivalent proportion of $P$. falciparum and $P$. vivax cases. This is explained by the fact that most reported cases were from Chocó and Nariño departments, where the population is mainly composed of African descendant communities with a high prevalence of Duffy negative individuals [37]. The lack of the Duffy Antigen Receptor for Cytokines (DARC) on the red blood cell membrane prevents the development of $P$. vivax blood infections while allowing the normal invasion and development of P. falciparum [38-40].

Our results, based on the official SIVIGILA records and Colombian INS data, are in agreement with previous studies conducted in Colombia in which other approaches and data sets were used [22, 23, 26, 28, 41] as well as with studies in other endemic countries in the Americas [9, 10, 13, 15]. Studies carried out in the urban 
Table 2 Annual parasite indexes of the municipalities reporting urban malaria in Colombia from 2008 to 2012

\begin{tabular}{|c|c|c|c|}
\hline & AFI & $A V I$ & $A P I$ \\
\hline \multicolumn{4}{|l|}{ Chocó } \\
\hline Nóvita & 44.5 & 47.9 & 93.0 \\
\hline Lloró & 5.9 & 33.8 & 41.4 \\
\hline Tadó & 14.1 & 17.8 & 32.2 \\
\hline Istmina & 15.5 & 12.2 & 28.3 \\
\hline Atrato & 11.3 & 8.3 & 19.9 \\
\hline Condoto & 3.6 & 6.8 & 10.6 \\
\hline Quibdó & 5.1 & 3.2 & 8.6 \\
\hline El Litoral del San Juan & 2.2 & 3.0 & 5.2 \\
\hline \multicolumn{4}{|l|}{ Nariño } \\
\hline El Charco & 21.6 & 1.9 & 23.5 \\
\hline San Andrés de Tumaco & 3.9 & 1.1 & 5.0 \\
\hline La Tola & 4.0 & 1.0 & 5.0 \\
\hline Barbacoas & 1.0 & 0.6 & 1.5 \\
\hline \multicolumn{4}{|l|}{ Guaviare } \\
\hline Miraflores & 10.1 & 59.7 & 71.0 \\
\hline \multicolumn{4}{|l|}{ Guainía } \\
\hline Puerto Inírida & 0.2 & 7.1 & 7.4 \\
\hline \multicolumn{4}{|l|}{ Amazonas } \\
\hline Puerto Nariño & 0.0 & 2.2 & 2.2 \\
\hline \multicolumn{4}{|l|}{ Risaralda } \\
\hline Pueblo Rico & 0.1 & 2.0 & 2.1 \\
\hline \multicolumn{4}{|l|}{ Valle del Cauca } \\
\hline Buenaventura & 0.1 & 0.4 & 0.5 \\
\hline
\end{tabular}

$A F I$ annual falciparum index, $A V I$ annual vivax index, API annual parasitic index area of Buenaventura (Valle del Cauca) between 1987 and 1993 found that urban malaria had a tendency towards quadrennial occurrence of epidemic peaks with targeted distribution of cases and a greater proportion of cases in men. However, the prevalence of $P$. falciparum infection was significantly greater and the most affected groups were those of extreme ages ( $<5$ and $\geq 60$ years of age) [23], whereas in our study malaria cases were more prevalent in the 20-29 years of age range and the lowest incidence was after 60 years of age.

Previous studies have found that the main breeding sites for malaria peri-urban vector were located in excavations left by the miners, as well as lakes and ponds dedicated to fish farming where immature An. nuneztovari and An. albimanus mosquito species with peri-domiciliary adult bite rates up to 7.1 were also found [28]. Even though a study in urban areas of Quibdó (Chocó) found 839 positive cases recorded as urban malaria cases $(77 \%$ of which were due to P. falciparum), only $24.4 \%$ of these were confirmed as indigenous urban malaria cases [22]. Malaria transmission appeared to be focused on periurban areas for both $P$. falciparum and $P$. vivax, with the greatest risk of transmission in proximity to areas of vegetation and excavations left by miners. The occurrence of malaria in children, students and housewives suggests that malaria transmission takes place inside households and at school neighborhoods [22]. Other focal studies such as the one conducted in Puerto Gaitán in the department of Meta located in the Eastern region of

Table 3 Entomological information

\begin{tabular}{|c|c|c|c|c|}
\hline Region & Department & Municipality & Anopheline species & References \\
\hline \multirow[t]{3}{*}{ Pacific coast } & Chocó & & $\begin{array}{l}\text { An. nuneztovari } \\
\text { An. neivai } \\
\text { An. darlingi } \\
\text { An. albimanus } \\
\text { An. pseudopunctipennis } \\
\text { An. punctimacula } \\
\text { An. lepidotus } \\
\text { Anopheles spp. }\end{array}$ & {$[21,22]$} \\
\hline & Valle del Cauca & Buenaventura & $\begin{array}{l}\text { An. nuneztovari } \\
\text { An. albimanus } \\
\text { An. neivai } \\
\text { An. pseudopunctipennis } \\
\text { An. albimanus }\end{array}$ & {$[21,23,27,28]$} \\
\hline & Nariño & & $\begin{array}{l}\text { An. neivai } \\
\text { An. albimanus } \\
\text { An. pseudopunctipennis } \\
\text { An. punctimacula }\end{array}$ & {$[21]$} \\
\hline \multirow[t]{3}{*}{ Orinoquia and Amazonia } & $\begin{array}{l}\text { Guainía } \\
\text { Guaviare }\end{array}$ & $\begin{array}{l}\text { Puerto Inírida } \\
\text { Miraflores }\end{array}$ & An. darlingi & {$[21,34]$} \\
\hline & Amazonas & & $\begin{array}{l}\text { An. darlingi } \\
\text { An. nuneztovari }\end{array}$ & {$[21]$} \\
\hline & Risaralda & Pueblo Rico & $\begin{array}{l}\text { An. albimanus } \\
\text { An.pseudopunctipennis }\end{array}$ & {$[21]$} \\
\hline
\end{tabular}


Colombia have reported similar results. In Puerto Gaitán $70 \%$ of the 192 malaria cases reported in 2009 were from urban areas; whereas in 2010 malaria cases increased to 226 with only $46 \%$ being urban [24, 42].

There is a contrast between the decreasing trend of rural malaria and the stable or increasing records on urban malaria. This might be explained by multiple conditions that could favor the introduction of malaria into peri-urban and urban areas. In Colombia population movements from endemic rural areas is mostly due to the ongoing armed conflict, but more recently also to the dissemination of illegal mining and proliferation of illicit crops; all of these generate fear and threaten safety in rural communities. Additionally, the lack of incentives for rural communities to remain in their regions as well as the apparent stimulus by the government for urban population with the hope for better jobs, encourage the migration from rural to urban and peri-urban areas. The migration of malaria infected individuals contributes to generate conditions for the introduction and maintenance of Plasmodium transmission [43] in peri-urban and urban areas. A recent study showed a significant number of malaria asymptomatic carriers who were able to efficiently infect mosquitoes despite the presence of low sub-microscopic parasitaemia [37].

Interestingly, in this study records of complicated malaria cases as well as malaria in pregnant women were found. In a previous study carried out in some of the same localities, most febrile patients in endemic areas attended the diagnostics service within 5 days of the onset of malaria symptoms [21,44] which may help prevent the development of complicated cases [45] Additionally, during the last two decades, Colombia has significantly increased its social security coverage, which would be expected to result in improved prenatal followup [46].

This study aimed at a better characterization of the reported urban and peri-urban malaria transmission and could serve as a reference transmission baseline at national scale to be further used for monitoring activities to evaluate compliance with the goal established by the INS-ETV (Vector-borne diseases) of eliminating urban and peri-urban malaria in Colombia by 2021. Although urban areas display different exposure risks and offer better opportunities for prevention and timely control due to the existing infrastructure, technological capabilities and access to health services [3, 47, 48], defining urban and peri-urban areas remains a challenge. The study was based on the SIVIGILA records in which the urban and peri-urban concepts are defined based on administrative factors that not necessarily take into consideration the ecology i.e., the presence of water collection, mosquitoes breeding sites, bushes and other more rural conditions.
This limitation, as well as the need to unify operational criteria for improving the quality and consistency of information, improving the malaria detection system, and timely control and monitoring supported by a geographic information system, should be addressed to unequivocally confirm the extent of urban and peri-urban malaria in Colombia. Besides the lack of an appropriate definition of urban, peri-urban and rural limits in most endemic areas studied, reliability and quality of available information are affected by a potential reporting bias due to case misclassification induced by the lack of proper verification of the geographical source of infection. Patient information is not always reliable $[21,25,48]$ or there may be bad processing of the mandatory format for reporting infectious diseases. For example, for safety reasons patients avoid providing information about the potential site of infection frequently related to areas of illegal activities. In addition, malaria control officers may not receive appropriate instruction or be aware of the critical importance of properly recording the geographical origin of the infection. Moreover, frequently the place of occurrence or origin of the case is confused with the place of temporal or permanent residence or the case report site.

Although malaria in urban residents has been conclusively shown, it remains critical to determine the extent of local transmission, including the definition of associated entomological factors such as presence of mosquito breeding places, abundance and behaviour of adult Anopheles. Environmental factors including precipitation, relative humidity and temperature also affect mosquito breeding [28] and must be further studied.

\section{Conclusions}

Despite the limitations described, this study documents the probable presence of endemic, unstable and lowintensity urban and peri-urban malaria cases in a group of municipalities located mainly on the Pacific coast region and a few others in the Eastern region. This study explored some key epidemiological factors related to malaria transmission in the urban settings selected to set up the grounds for ongoing prospective studies aimed at unequivocally confirming the urban or peri-urban origin of the malaria cases and the transmission conditions to aid in achieving the goal of urban malaria elimination in Colombia by 2021.

\section{Authors' contributions}

JP and PC conceived the manuscript and provided the information. KM, MA and $\mathrm{SH}$ generated the initial manuscript. All authors contributed the data analyses. All authors read and approved the final manuscript.

\section{Author details}

${ }^{1}$ Ministerio de Salud y Protección Social de Colombia, Bogotá, Colombia. ${ }^{2}$ Instituto Nacional de Salud, Bogotá, Colombia. ${ }^{3}$ Malaria Vaccine and Drug 
Development Center, Cali, Colombia. ${ }^{4}$ Faculty of Health, Universidad del Valle, Cali, Colombia. ${ }^{5}$ Centro de Investigación Científica Caucaseco, Cali, Colombia.

\section{Acknowledgements}

We thank the support of the Sub-dirección de Vigilancia y Control en Salud Pública-INS and to SIVIGILA for making the data available. Sergio Ochoa for drafting part of the manuscript. This work was supported by the Ministry of Health of Colombia, as well as by Colciencias (research grant 360-2011; 7192013) and the US-NIAID/ICEMR (research grant U19AI089702).

\section{Competing interests}

The authors declare they do not have any competing interest.

Received: 1 October 2015 Accepted: 21 October 2015

Published online: 14 November 2015

\section{References}

1. WHO. World malaria report 2013. Geneva: World Health Organization; 2013

2. Hay SI, Guerra CA, Tatem AJ, Atkinson PM, Snow RW. Tropical infectious diseases: urbanization, malaria transmission and disease burden in Africa. Nat Rev Microbiol. 2005;3:81-90.

3. Caldas de Castro M, Yamagata Y, Mtasiwa D, Tanner M, Utzinger J, Keiser J, et al. Integrated urban malaria control: a case study in Dar es Salaam, Tanzania. Am J Trop Med Hyg. 2004;71:103-17.

4. Robert V, Macintyre K, Keating J, Trape J-F, Duchemin J-B, Ukwuani F, et al. Malaria transmission in urban sub-Saharan Africa. Am J Trop Med Hyg. 2003;68:169-76

5. Dash A, Valecha N, Anvikar A, Kumar A. Malaria in India: challenges and opportunities. J Biosci. 2008;33:583-92.

6. Sharma V. Malaria and poverty in India. Curr Sci. 2003:84:513-5.

7. Hyma B, Ramesh A, Chakrapani K. Urban malaria control situation and environmental issues, Madras City, India. Ecol Dis. 1982;2:321-35.

8. Cator LJ, Thomas S, Paaijmans KP, Ravishankaran S, Justin JA, Mathai MT, et al. Characterizing microclimate in urban malaria transmission settings: a case study from Chennai, India. Malar J. 2013;12:84.

9. Bautista CT, Chan AS, Ryan JR, Calampa C, Roper MH, Hightower AW, et al. Epidemiology and spatial analysis of malaria in the Northern Peruvian Amazon. Am J Trop Med Hyg. 2006;75:1216-22.

10. Marques AC. Migrations and the dissemination of malaria in Brazil. Mem Inst Oswaldo Cruz. 1986;81:17-30.

11. Oliveira-Ferreira J, Lacerda MV, Brasil P, Ladislau JL, Tauil PL, Daniel-Ribeiro CT. Malaria in Brazil: an overview. Malar J. 2010;9:115.

12. Saraiva MdGG, Amorim RDS, Moura MAS, Martinez-Espinosa FE, Barbosa MdGV. Expansão urbana e distribuição espacial da malária no município de Manaus, Estado do Amazonas. Rev Soc Bras Med Trop. 2009:42:515-22.

13. Gonçalves MJF, Alecrim WD. Non-planed urbanization as a contributing factor for malaria incidence in Manaus-Amazonas, Brazil. Rev de Salud Públ. 2004:6:156-66.

14. Tada MS, Marques RP, Mesquita E, Martha RCD, Rodrigues JA, Costa JD, et al. Urban malaria in the Brazilian Western Amazon region I: high prevalence of asymptomatic carriers in an urban riverside district is associated with a high level of clinical malaria. Mem Inst Oswaldo Cruz. 2007; 102:263-70

15. Gil LHS, Tada MS, Katsuragawa TH, Ribolla PEM, Silva LHPd. Urban and suburban malaria in Rondônia (Brazilian Western Amazon) II: perennia transmissions with high anopheline densities are associated with human environmental changes. Mem Inst Oswaldo Cruz. 2007:102:271-6.

16. San Sebastián M, Játiva R, Goicolea I. Epidemiology of malaria in the Amazon basin of Ecuador. Rev Panam de Salud Púb. 2000;7:24-8.

17. Vargas J, Elgegren J, San Miguel A, Cardozo R. Malaria en una población urbano marginal de lquitos. Rev Peru de Epidemiol. 2003:11:1-6.

18. Branch O, Casapia WM, Gamboa DV, Hernandez JN, Alava FF, Roncal N, et al. Clustered local transmission and asymptomatic Plasmodium falciparum and Plasmodium vivax malaria infections in a recently emerged, hypoendemic Peruvian Amazon community. Malar J. 2005;4:27.

19. Rosas-Aguirre A, Llanos-Cuentas A, Speybroeck N, Cook J, Contreras-Mancilla J, Soto $V$, et al. Assessing malaria transmission in a low endemicity area of north-western Peru. Malar J. 2013;12:339.
20. Arróspide N, Miranda E, Casas JV. Malaria urbana por Plasmodium vivax en La Molina, Lima. Rev Peru de Epidemiol y Salud Pub. 2007;24:192-3.

21. Herrera S, Quinones ML, Quintero JP, Corredor V, Fuller DO, Mateus JC, et al. Prospects for malaria elimination in non-Amazonian regions of Latin America. Acta Trop. 2012;121:315-23.

22. Ochoa J, Osorio L. Epidemiología de malaria urbana en Quibdó, Chocó. Biomedica. 2006:26:278-85.

23. Méndez F, Carrasquilla G. Epidemiología de la malaria en el área urbana de Buenaventura: análisis de la ocurrencia en el periodo 1987-1993. Colombia Médica. 1995;26:77-85.

24. Buitrago LS, McKeon SN, Lainhart W, Conn JE. First published record of urban malaria in Puerto Gaitan, Meta, Columbia. Mem Inst Oswaldo Cruz. 2013;108:1045-50.

25. Osorio L, Todd J, Bradley DJ. Travel histories as risk factors in the analysis of urban malaria in Colombia. Am J Trop Med Hyg. 2004;71:380-6.

26. Mendez F, Carrasquilla G, Muñoz A. Risk factors associated with malaria infection in an urban setting. Trans R Soc Trop Med Hyg. 2000;94:367-71.

27. Montoya-Lerma J, Solarte YA, Giraldo-Calderon Gl, Quinones ML, RuizLopez F, Wilkerson RC, et al. Malaria vector species in Colombia: a review. Mem Inst Oswaldo Cruz. 2011;106(Suppl 1):223-38.

28. Olano V, Carrasquilla G, Mendez F. Transmisión de la malaria urbana en Buenaventura, Colombia: aspectos entomológicos. Rev Panam Salud Publ. 1997;1:287-94

29. Ahumada ML, Pareja PX, Buitrago LS, Quinones ML. Biting behavior of Anopheles darlingi Root, 1926 (Diptera: Culicidae) and its association with malaria transmission in Villavicencio (Meta, Colombia. Biomedica. 2013;33:241-50 (in Spanish).

30. Brochero HL, Rey G, Buitrago LS, Olano VA. Biting activity and breeding sites of Anopheles species in the municipality Villavicencio, Meta, Colombia. J Am Mosq Control Assoc. 2005;21:182-6.

31. Colombia MdSyPSd. Estrategia de Gestión Integrada para la promoción, prevención y control de las Enfermedades Transmitidas por Vectores en Colombia, 2012-2021. In: Colombia MdSyPSd, editor. Ministerio de Salud y Protección Social de Colombia; 2012.

32. Plan Decenal de Salud Pública 2012-2021: La salud en Colombia la construyes tú. Ministerio de Salud y Protección Social 2013;124.

33. Instituto Nacional de Salud de Colombia. Manual para Análisis: Indicadores para la vigilancia de eventos de interés en salud pública; 2012.

34. Olano V, Brochero H, Sáenz R, Quiñones ML. Mapas preliminares de la distribución de Anopheles vectores de malaria en Colombia. Biomédica. 2001;21:402-3.

35. Departamento Administrativo Nacional de Estadística. DANE. Censo Poblacional. http://www.dane.gov.co/censo/files/libroCenso2005nacional.pdf2005. Accessed 10 July 2015.

36. Chaparro P, Padilla J, Vallejo AF, Herrera S. Characterization of a malaria outbreak in Colombia in 2010. Malar J. 2013;12:330.

37. Vallejo A, Chaparro P, Benavides Y, Álvarez Á, Quintero J, Padilla J, ArévaloHerrera M, Herrera S. High prevalence of sub-microscopic infections in Colombia. Malar J. 2015;14:201.

38. Zimmerman PA, Ferreira MU, Howes RE, Mercereau-Puijalon O. Red blood cell polymorphism and susceptibility to Plasmodium vivax. Adv Parasitol. 2013;81:27-76.

39. Carvalho GBd, Carvalho GBd. Duffy blood group system and the malaria adaptation process in humans. Rev Bras Hematol Hemoter. 2011;33:55-64

40. Herrera S, Gómez A, Vera O, Vergara J, Valderrama-Aguirre A, Maestre A, et al. Antibody response to Plasmodium Vivax antigens in Fy- negative individuals from the Colombian Pacific Coast. Am J Trop Med Hyg. 2005;73:44-9

41. Osorio L, Todd J, Pearce R, Bradley DJ. The role of imported cases in the epidemiology of urban Plasmodium falciparum malaria in Quibdó, Colombia. Trop Med Int Health. 2007;12:331-41.

42. Morales AJR, Canizales CEJ, Herrera AC, Medina A, Martínez JW. Patrones de comportamiento de la malaria en el departamento de Risaralda, Colombia, 2007-2009. Rev Med de Risaralda. 2012;18:65-71.

43. Martens P, Hall L. Malaria on the move: human population movement and malaria transmission. Emerg Infect Dis. 2000;2:103-9.

44. Lopez-Perez M, Alvarez A, Gutiérrez J, Moreno A, Herrera S, ArévaloHerrera M. Malaria-related anemia in patients from unstable transmission areas in Colombia. Am J Trop Med Hyg. 2015;92:294-301. 
45. O'Brien AT, Ramirez JF, Martinez SP. A descriptive study of 16 severe Plasmodium vivax cases from three municipalities of Colombia between 2009 and 2013. Malar J. 2014;13:404.

46. Jaramillo I. Evaluacion de la desentralizacion de la salud y la reforma de la Seguridad Social en Colombia. Gas Sanit. 2002;16:48-53.

47. Nájera JA, Kouznetsov R, Delacollette C. Malaria epidemics: detection and control, forecasting and prevention. In: World Health Organization, WHO/ MAL/98-1084, Geneva; 1998.
48. Siri JG, Lindblade KA, Rosen DH, Onyango B, Vulule J, Slutsker L, et al. Quantitative urban classification for malaria epidemiology in sub-Saharan Africa. Malar J. 2008;7:34.

\section{Submit your next manuscript to BioMed Central} and take full advantage of:

- Convenient online submission

- Thorough peer review

- No space constraints or color figure charges

- Immediate publication on acceptance

- Inclusion in PubMed, CAS, Scopus and Google Scholar

- Research which is freely available for redistribution

Submit your manuscript at

www.biomedcentral.com/submit

() Biomed Central 